\title{
EFFECT OF HEATING AND IRRADIATION ON TOTAL PHENOLICS (TP) CONTENT IN SELECTED WHOLE AND DEHULLED MILLET GRAINS
}

\section{SUJATHA. M \& HYMAVATHI. T. V}

Post Graduate \& Research Centre, Professor Jayashankar Telangana State Agricultural University, Hyderabad, India

ABSTRACT
The present investigation was conducted, to find out the effects of heat or irradiation, combined with heat on
total Phenolic content (TPC). Sorghum, pearl millet, foxtail millet was used in the study. Whole (WC) and dehulled (DC)
grains were treated either with heat $\left(170^{\circ} \mathrm{C}\right)$ or irradiation at $1.0 \mathrm{kGy} / 2.5 \mathrm{k}$ y, and stored for 90 days. There was a
significant (p<0.05) effect of treatments, storage and grain, and their interactions on the nutritional quality parameters
with a result in a decrease in TPC. The mean TPC was 188.5 (Pyrocatechol equivalent) percent, respectively. The
Phenolic content of DC and WC grains was 203.56 and 225.36, respectively. Heat treatment alone resulted in 4.3 and 7.9
percent reduction and irradiation combination treatment, resulted in 20.3 and 22 reductions in the TPC of WC and DC.
Among the three millets, irrespective of whole and dehulled, highest reduction was in sorghum, followed by foxtail millet
and pearl millet. Significantly, higher (p<0.05) reduction was found in foxtail millet (38.14\%), followed by sorghum
(34.26\%) and pearl millet (12.89\%) grain. During storage maximum loss reduction was in sorghum, followed by foxtail
millet and pearl millet.
KEYWORDS: Total Phenolic Content (TPC), Whole (WC) and Dehulled (DC) \& Foxtail Millet and Pearl Millet

Received: Aug 10, 2017; Accepted: Aug 31, 2017; Published: Oct 05, 2017; Paper Id.: IJASROCT201752

\section{INTRODUCTION}

Irradiation is one of the processing technologies, currently available for the inactivation of microorganisms, and it has been proven successful in ensuring the safety and extending the shelf life of foods (Mahapatra et al., 2005). Irradiation is also recognized to cause fewer overall physical and sensory changes than cooking, freezing, or canning (Molins, 2001). As irradiation is a physical process, no external additives are involved. The irradiation process is, therefore, useful and desirable as an alternative in the preservation and processing of various fresh, perishable, and high-protein foods, with or without chemical additives or biological controls (Lochhead, 1989 and Murray, 1990).

During storage, there may be some nutritional changes to the cereals, although for dry grains these changes will be small, even over a period of several months. If grains are stored with a higher than ideal moisture content, grain and microbial amylases may begin to break down the starch, leading to a deterioration of grain quality. Several methods of drying are employed, to reduce the moisture content to desirable levels. The effect of heating before irradiation is additive or slightly more than additive, ionizing radiation applied before heating is strongly synergistic, in the inactivation of bacterial spores (Gombas and Gomez., 1978). High temperatures applied before radiation, sensitize insects to radiation and hence, allow the use of low dose (Tilton and Browser 1987). The chemical structure of irradiated food is less modified than heat-treated one, and this technique avoids the use of potentially harmful chemicals (Siddhuraju et al., 2002). 
Gamma irradiation is capable of hydrolyzing chemical bonds, thereby leaving large molecules of starch into smaller fragments of dextrin, that may be either electrically charged or uncharged as free radicals. Irradiation of gamma rays on bud wood can produce higher frequencies of mutation, leading to the creation of new variants, compared to the control. Macronutrients (carbohydrates, proteins and lipids) content is relatively stable, against irradiation doses up to 10 $\mathrm{kGy}$, on the other hand, gamma irradiation affects proteins by causing conformational changes, oxidation of amino acids, rupturing of covalent bonds and formation of protein free radicals. (Issa et al., 2011).

Millets are rich in bioactive phytochemicals, particularly phenolic acids and Phenolic compounds in millets are found in the soluble, as well as insoluble-bound forms. Both hydroxybenzoic and hydroxycinnamic acids and their derivatives are notably present in different types of millet grains, in varying proportion. (Chandrasekara and Shahidi, 2011).

Compared with other major cereals, millets remain much under-studied and under-utilized, though there has been increased interest in their utilization, in recent years. Understanding the properties, structure, and potential uses of millets nutritional quality greatly contributes to the further development of millets, as alternative functional crops. However, there are some studies on the protein of millet grains and as effected by processing, such as fermentation, germination on improvement of Total phenolics. However, there were no studies found in the literature on the irradiation effect on the Total phenolics on different millets.

\section{MATERIALS AND METHODS}

Millet processing and heating were carried out at millet processing centre; grains were irradiated at the irradiation unit of PJTSAU. The chemical analysis was conducted at the department of foods and nutrition, Post Graduate and Research centre of the university. Sorghum and foxtail millet grains were collected from RARS, Nandyal, ANGRAU and pearl millet from RARS, Palem, PJTSAU. All the grains were stored in polythene bags, until used under dry and cool conditions, away from insects and pests. The grains were dehulled in an abrasive dehuller (Gurunanak Engineering Co, Hyderabad) up to $17 \%$ removal of bran. In the present, experiment electric rotary dryer (S K Engineering, New Delhi) was used, which can be operated continuously for large quantity of grain. Whole and dehulled grains of $5 \mathrm{~kg}$ all three millets were exposed to heat treatment, at a temperature of $150-170^{\circ} \mathrm{C}$ for $1.5 \mathrm{~min}$ at $300 \mathrm{rpm}$. The millet grains were irradiated using cobalt - 60 gamma sources. Two different dosages $1.0 \mathrm{kGy}$ and $2.5 \mathrm{kGy}$ were used. Grains of $500 \mathrm{~g}$ were packed in polythene pouches and exposed to the irradiation.

Total phenolics were estimated according to the procedure of Slinkard and Slingleton, (1997). The total phenolic content of alkaline extracts from the grains, and their insoluble and soluble defeated fractions will be assayed by FolinCiocalted method. It measures the absorbance of the blue colored complex, formed by the reaction between phenolic compounds and Folin-Ciocalteu reagent.

\section{Procedure}

$1 \mathrm{ml}$ of the extract was diluted with $46 \mathrm{ml}$ of distilled water. Then, 1 milliliter of Folin ciocalteu reagent was added, and the mixture was stirred vigorously. $3 \mathrm{ml}$ of $\mathrm{Na}_{2} \mathrm{CO}_{3}(2 \%)$ was added after $3 \mathrm{~min}$ and then was allowed to stand for $2 \mathrm{hrs}$, with intermittent shaking. After that, absorbance was measured at 760nm in spectrophotometer against blank, consisting of all the reaction agents except the extract. The total phenol content in the extract determined as microgram of pyrocatechol equivalent, according to the equation that was obtained from standard pyrocatechol graph as, 
Absorbance $=0.0021 \times$ Total Phenol $(\mu$ g pyrocatechol $)-0.0092$

\section{Storage Studies}

All the treated grains with a control sample of $500 \mathrm{gm}$ were stored for $30,60,90$ days, in HDPE pouches at $34^{\circ} \mathrm{C}$ to $36^{\circ} \mathrm{C}$ of temperature and $23 \%$ of humidity. The estimations were done at the end of $30^{\text {th }}$ day, $60^{\text {th }}$ day and, $90^{\text {th }}$ day.

\section{Study Design}

The study was conducted using $3 \times 8 \times 4$ factorial design, which means 3 types of grains, 8 types of treatments and 4 levels of storage were used for the study. The effects of these factors were studied on total phenolics. The details are given in Table 1.

Table 1: The Details of Treatments Used in the Study

\begin{tabular}{|c|l|l|c|}
\hline $\begin{array}{c}\text { SI. } \\
\text { No }\end{array}$ & \multicolumn{1}{|c|}{ Treatments (8) } & \multicolumn{1}{|c|}{ Grains (3) } & $\begin{array}{c}\text { Storage } \\
\text { Period (4) }\end{array}$ \\
\hline 1 & Control -Whole grain & Sorghum & 0 Day \\
\hline 2 & Control- Dehulled grain & Pearl Millet & $30^{\text {th }}$ day \\
\hline 3 & Heat treated -Whole grain & Foxtail Millet & $60^{\text {th }}$ day \\
\hline 4 & Heat treated -Dehulled grain & & $90^{\text {th }}$ day \\
\hline 5 & Heat and 1.0kGy Irradiated -Whole grain & & \\
\hline 6 & Heat and 2.5kGy Irradiated - Whole grain & & \\
\hline 7 & Heat and 1.0kGy Irradiated -Dehulled grain & & \\
\hline 8 & Heat and 2.5kGy Irradiated - Dehulled grain & & \\
\hline
\end{tabular}

All the results were statistically analyzed using IBM SPSS statistics 20 software. The Multifactor ANOVA technique was used to test, to find out the significant effect of treatments on TPC of the millet grains.

\section{RESULTS AND DISCUSSIONS}

In the study, whole and dehulled grains of Sorghum, Pearl millet and foxtail millet were used as controls to investigate the effects of heating and irradiation on the Total phenolics (TPC). Within irradiation, $1.0 \mathrm{kGy}$ and $2.5 \mathrm{kGy}$ dosages were employed. The irradiated grains were stored for 90 days and repeated analysis was conducted at 30 days duration.

\section{Effect of Treatments, Storage and Grain on Total Phenolic Content (TPC) of Millets}

The TPC in whole control grain ranged from 203 to 297 ( $\mu$ g equivalent Pyrocatetochol) percent, and in dehulled control grain from 183.42 to 259.61 ( $\mu \mathrm{g} /$ Pyrocatetochol equivalent/) (Table 2). Maximum quantity was found in pearl millet, followed by foxtail millet and sorghum. Hag et al. (2002) also showed that, dehulling decreased the TPC in pearl millet. Tian et al. (2004) reported that, phenolic compounds are concentrated in the bran layers and are liable for losses, during the separation of the seed coat in the milling process. Histo chemical localisation of phenolic compounds in the millet kernel indicated that, the phenolics are mainly concentrated in the test or seed coat layers (Shobana et al., 2009).

Table 2: Effect of Treatment, Storage and Grain Type on Phenolics

\begin{tabular}{|l|c|}
\hline Main Effects & TPC( $\boldsymbol{\mu g} /$ Pyrocatechol $) \%$ \\
\hline Treatment & \\
\hline DC & $203.567 \pm 0.01$ \\
\hline DEHE & $186.932 \pm 0.02$ \\
\hline DEHEI1.0 & $163.114 \pm 0.02$ \\
\hline DEHEI2.5 & $153.514 \pm 0.03$ \\
\hline
\end{tabular}




\begin{tabular}{|l|c|}
\hline \multicolumn{2}{|c|}{ Table 2: Contd., } \\
\hline WC & $225.363 \pm 0.03$ \\
\hline WHE & $215.809 \pm 0.02$ \\
\hline WHEI1.0 & $189.157 \pm 0.01$ \\
\hline WHEI2.5 & $170.173 \pm 0.02$ \\
\hline Storage & \\
\hline $0^{\text {th }}$ day & $206.255 \pm 0.02$ \\
\hline $30^{\text {th }}$ day & $194.236 \pm 0.02$ \\
\hline $60^{\text {th }}$ day & $182.44 \pm 0.02$ \\
\hline $90^{\text {th }}$ day & $170.884 \pm 0.03$ \\
\hline Grains & \\
\hline Foxtail Millet & $192.343 \pm 0.02$ \\
\hline Sorghum & $137.775 \pm 0.01$ \\
\hline Pearl Millet & $235.243 \pm 0.01$ \\
\hline
\end{tabular}

*Significant at $\mathrm{p}=0.05$, values with similar superscripts are not significantly different with each other $(\mathrm{p}>0.05)$

In the studies conducted by Chandrasekara and Shahidi (2011), phenolic compounds varied with the type of millet and morphological fraction of the grain. (Chethan and Malleshi, 2007). Phenolic compounds are secondary plant metabolites, and their type and content in the grains may depend on a number of factors, such as the type of cereal, variety, part of the grain, climatic conditions, and cultivation practices, among others (Shahidi and Naczk, 2004). Sorghum has a total phenolic content, ranging from 3 to $43 \mathrm{mg} / 100 \mathrm{~g}$ (Sikwese and Duodu, 2007). Phenolic content varies with the kind of extraction used and standard used.

In sorghum, Youssef et al. (1988), reported reduction in phenolics in the order of 70-85 percent, due to decortication to 70 percent extraction rate. Dlamini et al. (2007), observed reductions of 33-77\% in sorghums of $70-81 \%$ extraction rates. Chiremba et al. (2009) also found that, decortication of sorghum to $70 \%$ extraction rate, reduced total phenolic content by 43-66\%. Similar results have been reported for pearl millet (Mohamed et al., 2010; Hag et al., 2002) and finger millet (Viswanath et al., 2009). Decortication reduced total phenolics and antioxidant activity, by about $80 \%$ in lentils and $30 \%$ in yellow peas (Han and Baik, 2008).

With regards to the overall treatment effect, a significant reduction in TPC was observed, due to heating as well as irradiation combination treatment, Table 3. $(\mathrm{p}<0.05)$. Heating alone resulted in 4.3 and 7.9 percent, and heating combined with irradiation resulted in 20.3 and 22 percent reduction in the TPC of WC and DC grains, respectively (Figure 1). More reduction due to irradiation was observed in WC (16 percent), than in DC (14.1 percent). It can be observed that, due to dehulling there was a 10 percent reduction in TPC, while due to irradiation it was 16 percent.

Table 3: ANOVA for the Effects of Treatment, Grain Type and Storage on Total Phenolic Content

\begin{tabular}{|l|c|c|c|c|}
\hline \multirow{2}{*}{\multicolumn{1}{c|}{ Source }} & \multirow{2}{*}{\begin{tabular}{c}
$\boldsymbol{D} \boldsymbol{F}$ \\
\cline { 3 - 5 }
\end{tabular}} & $\boldsymbol{M S}^{\boldsymbol{b}}$ & $\boldsymbol{F}^{\boldsymbol{c}}$ & $\boldsymbol{P}^{\boldsymbol{d}}$ \\
\hline MAIN EFFECTS & & & & \\
\hline Treatment (T) & 7 & 15561.8 & 21873163.27 & 0.0000 \\
\hline Grain Type (G) & 2 & 152724. & 214663613.44 & 0.0000 \\
\hline Storage(S) & 3 & 11123.2 & 15634406.79 & 0.0000 \\
\hline INTERACTIONS & & & & \\
\hline TG & 14 & 1256.05 & 1765456.86 & 0.0000 \\
\hline TS & 21 & 67.6989 & 95155.09 & 0.0000 \\
\hline GS & 6 & 68.2041 & 95865.17 & 0.0000 \\
\hline TGS & 42 & 38.4865 & 54095.24 & 0.0000 \\
\hline
\end{tabular}


- Degrees of Freedom,

- $\quad$ Mean Square,

- F-Ratio g-Total phenolic content

- P-Value,

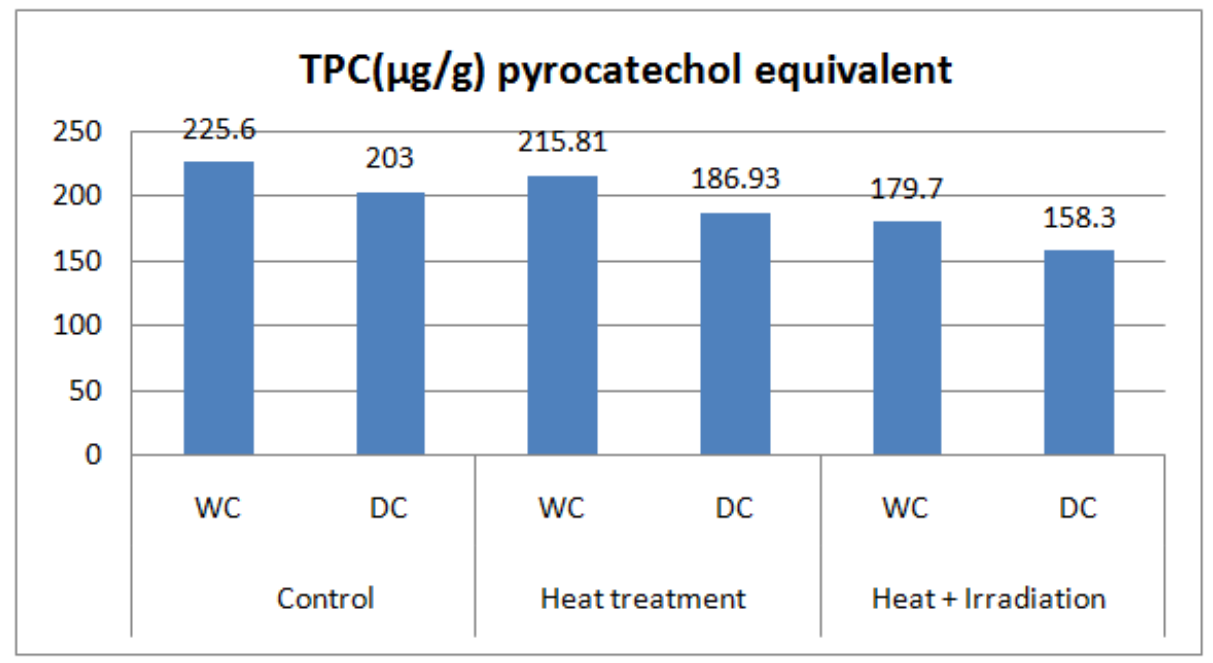

Figure 1: Total Phenolic Content of Millets as Affected by Heat and Irradiation

\section{Combination Treatment}

WC - Whole control, DC- Dehulled control

The present results helps to make use of irradiation as a processing method, to reduce phenolic content without the use of mechanical dehulling, which is time consuming than the earlier. In black rice, irradiation at 2, 4 , and $6 \mathrm{kGy}$ significantly reduced their total phenolic acid content $(314.8,332.2$, and $268.9 \mathrm{mg} / \mathrm{kg}$, respectively), as compared with control $(381.6 \mathrm{mg} / \mathrm{kg})$. However, irradiation at $8 \mathrm{kGy}$ achieved the highest total phenolic acid content $(423.3 \mathrm{mg} / \mathrm{kg})$. But, there are studies reporting no reduction in TPC, even at $10 \mathrm{kGy}$ irradiation compared with the control (Zhu et al., 2010).

Increases in phenolic content, due to irradiation have also been reported by various authors and this is attributed for the most part, to release phenolics from the food constituents to which they are bound, such as cell walls as a result of the irradiation process. Variyar et al. (2004), reported a significant decrease in total isoflavones and glycosides in soybean, with increased irradiation dose (0.5-5.0 kGy), however the aglycone content showed an increasing trend. Also, a significant increase in the percentage of DPPH scavenging activity, with increased gamma-irradiation was observed, probably related to the increased aglycone content. It was suggested that, irradiation can induce the breakdown of glycosides resulting in the release of free isoflavones.

Storage of grains up to 90 days in polyethylene at ambient temperature in general, significantly $(\mathrm{p}<0.05)$ reduced the initial TPC by 5.8, 11.54 and 17.14 percent in 30, 60 and 90 days, respectively. Further, it can also be observed that, the percent reduction from zero to 30,30 to 60 and 60 to 90 days was 5.8, 6.07 and 6.34 percent, indicating that, the percent loss between the equal duration of storage was almost nearer (Table.2). 
From the interaction effect of treatment and storage, it can be observed that, in untreated dehulled grains the reduction was 37.33 percent, whereas in treated grains, it was, 28.87, and 37.1 in DEHE, DEHE 1 and DEHE 2.5, respectively. However, untreated and DEHE1 grains are marginally different from each other. In case of untreated whole grains, the percent reduction was 45, while in treating grains, it was 40, 36.34 and 28.9 percent in WEHE, WEHE1 and WEHE 2.5, respectively. The effect of storage on the TPC reduction was more pronounced in whole grains than in dehulled grains. When the storage effect was observed grain wise, it can be observed that, significantly higher $(\mathrm{p}<0.05)$ reduction was found in foxtail millet (38.14\%), followed by sorghum (34.26\%) and pearl millet (12.89\%) grain. At 90 days storage, maximum reduction was found in sorghum $(21.61 \%)$, followed by foxtail millet $(16.42 \%)$ and pearl millet $(14.91 \%)$.

When treatment effect was considered grain wise, maximum reduction was found in dehulled sorghum due to heat alone and irradiation combined treatment, whilst least reduction was noted in pearl millet. Irradiation was relatively less effective in the TPC reduction in pearl millet over sorghum and foxtail millet. (Figure 2)

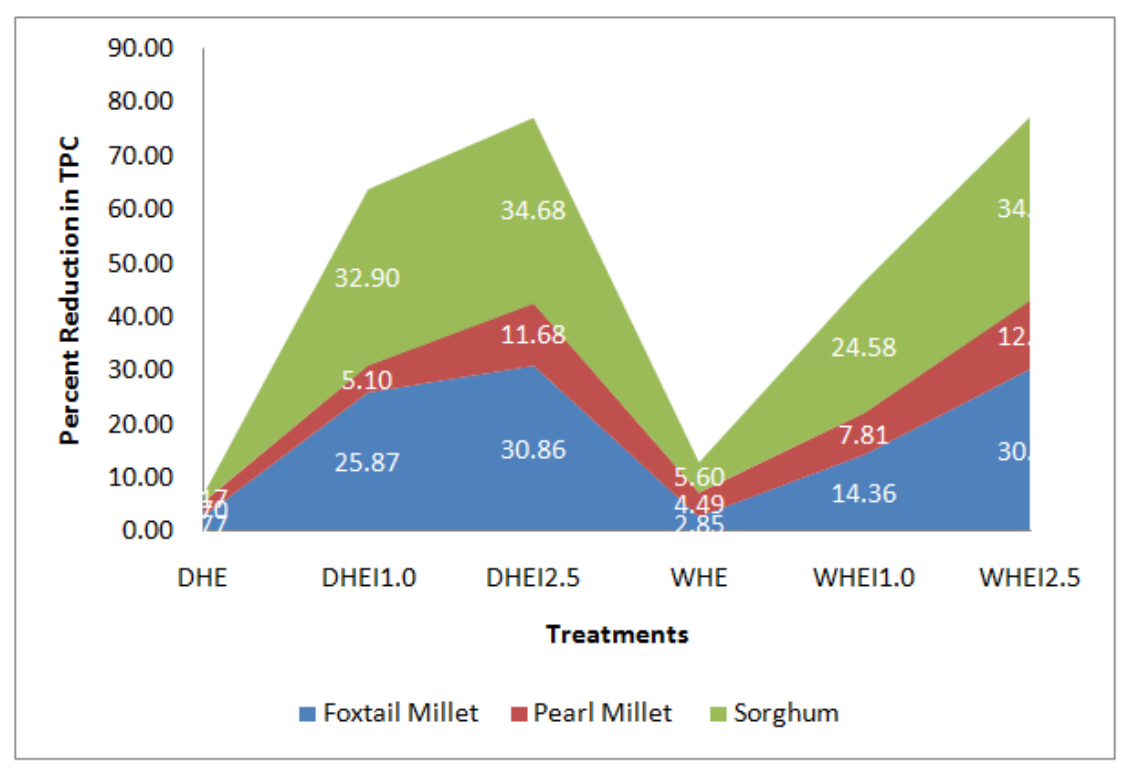

Figure 2: Percent Reduction in Total Phenolic Content in Treated Grains

DHE - Dehulled heat treated, DHE1.0-Dehulled heat and irradiated (1kGy)

DHE2.5-Dehulled heat and irradiated (2.5kGy), WHE - Whole heat treated

WHE1.0 Whole heat and irradiated (1.0kGy),

WHE2.5 - Whole heat and irradiated $(2.5 \mathrm{kGy})$

When the reductions in TPC were observed treatment wise, highest loss was found in DEHEI 2.5 (34.68\%) and WHE I 2.5 (34.26\%) of sorghum and least loss was noted in DHE of sorghum (1.17\%), followed by pearl millet (2.7\%). DHE1 1.0 could also reduce the TPC content, relatively to a higher extent in sorghum and foxtail millet, than in pearl millet. In pearl millet, highest reduction occurred only at $2.5 \mathrm{KGy}$ dosage (12.89\% in WC and $11.68 \%$ in DC), unlike other two grains, clearly indicating under the present study conditions pearl millet relatively had higher resistance to irradiation effect, than other two grains. 
These studies, along with other previous studies clearly suggest that, irradiation can either disrupt phenolics, as in the present study or can facilitate the antioxidant activities of some dietary plants, where low dose of $\gamma$-irradiation on citrus peels enhanced the synthesis of total phenolic compounds. (Horvathova et al., 2007 and Suhaj et al., 2006). The balance of the disruption and synthesis may depend on the irradiation dose. The studies with higher doses of irradiation of millets might help to understand this phenomenon, in a much better way.

\section{CONCLUSIONS}

The mean total phenolic content of the grains was 188.45 percent. Pearl millet has significantly highest TPC, followed by foxtail millet and sorghum. There was a significant negative effect of treatments on the TPC content, in general. Heat treatment reduced the TPC by 21.5 percent on an average, irrespective of the grain and storage, while a higher reduction of 15.05 percent occurred due to irradiation. Compared to the TPC reduction (9.67\%), due to dehulling at 17 percent used in the present study, relatively higher reduction was observed due to irradiation. These suggest that, in the TPC reduction stand point, irradiation could be a better processing method than dehulling. Storage studies revealed that, there was a gradual reduction of TPC, irrespective of grains and treatments during the 90 days storage period, with a maximum loss of 17.14 percent at 90 days and pearl millet had a maximum loss, among the three grains. However, the treated grains had a relatively less loss, compared to both whole and dehulled untreated grains; this will further strengthen the advantages of the irradiation processing of millets.

Overall, there were no serious adverse effects of irradiation treatment up to $2.5 \mathrm{kgs}$ in sorghum, pearl millet and foxtail millet. Irradiation in combination with heat treatment was found to be advantageous over heat treatment alone, in terms of reducing total Phenolic content.

\section{REFERENCES}

1. Chandrasekara, A and Shahidi, F. 2011. Determination of antioxidant activity in free and hydrolyzed fractions of millet grains and characterization of their phenolic profiles by HPLC-DAD-ESI-MS. Journal of Functional Foods. 3: 144-158.

2. Chethan, S and Malleshi, N.G. 2007. Finger millet polyphenols: Optimization of extraction and the effect of $p H$ on their stability. Food Chemistry. 105: 862-870.

3. Chiremba, C., Taylor, J. R. N and Duodu, K. G.2009. Phenolic content, antioxidant activity, and consumer acceptability of sorghum cookies. Cereal Chemistry. 86:590-594.

4. Dlamini, N. R., Taylor, J. R. N and Rooney, L. W.2007. The effect of sorghum type and processing on the antioxidant properties of African sorghum based foods. Food Chemistry.105:1412-1419.

5. Gombas, D.E and Gomez, R.F. 1978. Sensitization of Clostridium perfringens spores to heat by gamma radiation. Applied and Environmental Microbiology. 36(3):403-407.

6. Hag, M.E.E., Tinay, A.H.E and Yousif, N.E. 2002. Effect of fermentation and dehulling on starch, total polyphenols, phytic acid content and in vitro protein digestibility of pearl millet. Journal of Food Chemistry. 77:193-196.

7. Han, H., Baik, B-K.2008. Antioxidant Activity and Phenolic Content of Lentils (Lens culinaris), Chickpeas (Cicer arietinum L.), Peas (Pisum sativum L.) and Soybeans (Glycine max) and Their Quantitative Changes during Processing. International Journal of Food Science and Technology. 43:1971-1978.

8. Horvathova, J., Suhaj, M., Polovka, M., Brezova,V and Simko,P.2007.The influence of $\gamma$-irradiation on the formation of free radicals and antioxidant status of oregano (Origanum vulgare L.)Czech. Journal of Food Science. 25:131-143. 
9. Issa, P., Mehdi.B., Abolfazl. T and Mehdi.J.2011.The use of gamma irradiation in agriculture. African Journal of Microbiology Research. 5(32):5806-5811.

10. Lochhead, C.1989. The high-tech food process foes find hard to swallow. Food Technology.43:56-59.

11. Mahapatra A. K., Muthukumarappan, K., Julson, J. L. 2005. Applications of ozone, bacteriocins and irradiation in food processing. Food Science and Nutrition. 45(6):447-461.

12. Mohamed, E. A., Mohamed, A. I and Babiker, E.E. 2010. Effects of radiation process on total protein and amino acids composition of raw and processed pearl millet flour during storage. International Journal of Food Science.12 (3):281-295.

13. Molins, R.A.2001. Food irradiation: principles and applications. New York.

14. Murray, D.R.1990. Biology of food irradiations. New York.

15. Shahidi, F and Naczk, M. 2004. Phenolics in food and nutraceuticals. Boca Raton: FL, CRC press.1-82.

16. Shobana, S., Sreerama, Y. N and Malleshi, N. G. 2009. Composition and enzyme inhibitory properties of finger millet (Eleusine coracana L.) seed coat phenolics: Mode of inhibition of a -glucosidase and pancreatic amylase. Food Chemistry, 115: 1268-1273.

17. Siddhuraju, P., Makkar H.P.S and Becker, K. 2002. The effect of ionising radiation on antinutritional factors and the nutritional value of plant materials with reference to human and animal food. Food Chemistry. 78:187-205.

18. Sikwese, F.E and Duodu, K.G. 2007. Antioxidant effects of crude phenolic extracts from sorghum bran in sunflower oil in the presence of ferric ions. Food Chem. 104:324-331.

19. Slinkard, K., and Singleton, V. L. 1997. Total phenol analysis: Automation and Comparison with manual Methods. American Journal of Enology and Viticulture.28:49-55.

20. Suhaj,M., Racova,J., Polovka,M and Brezová.V. 2006. Effect of $\gamma$-irradiation on antioxidant activity of black pepper (Piper nigrumL).Food Chemistry. 97: 696-704.

21. Tian, S., Nakamura, $K$ and Kayahara, H.2004. Analysis of phenolic compounds in white rice, brown rice and germinated brown rice. Journal of Agricultural and Food Chemistry. 52: 4808-4813.

22. Tilton, E.W and Brower, J.H.1987. Ionizing radiaton for insect control in grains and grain products. Cereal Foods World. 32(2):330-335.

23. Variyar, P. S., Limaye, A and Sharma, A.2004. Radiation-induced enhancement of antioxidant contents of soybean (Glycine max Merrill).Journal of Agriculture and Food Chemistry. 52:3385-3388.

24. Viswanath, V., Urooj, A and Malleshi, N. G. 2009.Evaluation of antioxidant and antimicrobial properties of finger millet polyphenols (Eleusine coracana).Food Chemistry. 114:340-346.

25. Zhu,F., Zhong C.Y., Jinsong, B and Harold, C.2010. Effect of $\gamma$-irradiation on phenolic compounds in rice grain. Food Chemistry. 120(1):74-77. 